\title{
O JOGO AGONÍSTICO: LIBERDADE-PODER SEGUNDO FOUCAULT
}

\section{The agonistic game: freedom-power according to Foucault}

Ana Lúcia dos Santos e Santos ${ }^{1}$

RESUMO: No presente texto, pretendo abordar a seguinte questão: como as práticas de liberdade se efetivam segundo Foucault? Para tanto, é preciso compreender, primeiramente o que são tais práticas e como são possíveis de se realizarem. De modo geral, podemos dizer que as práticas de liberdade são ações de resistência que ocorrem por meio de uma atividade crítica e criativa face aos modos de individualização do sujeito - a partir das técnicas de vigilância que se encarregam de incitar e controlar os corpos, e a regulamentação totalizante da população. Essas práticas são possíveis, visto que nas relações sociais existe um jogo agonístico entre a liberdade e o poder que se revelam de forma circular - ora um domina ora a situação se inverte. Assim, cabe investigarmos o significado, a possibilidade, fato da existência da liberdade segundo Foucault, e em última análise os desdobramentos.

Palavras chaves: Prática. Liberdade. Resistência. Poder.

ABSTRACT: In this text, I intend to address the following question: how do freedom practices take place according to Foucault? To do so, it is necessary to understand, first, what such practices are and how they are possible to accomplish themselves. In general, we can say that freedom practices are actions of resistance that occur through a critical and creative activity in the face of the individualization modes of the subject - from the surveillance techniques that are in charge of inciting and controlling the bodies, and the totalizing regulation of the population. These practices are possible, since in social relations there is an agonistic game between freedom and power that are revealed in a circular way - now one dominates now the situation is reversed. Thus, it is necessary to investigate the meaning, the possibility, fact of the existence of freedom according to Foucault, and ultimately the unfolding.

Keywords: Practice. Freedom. Resistance. Power.

\footnotetext{
${ }^{1}$ Graduada em Filosofia pela Universidade Federal do Recôncavo da Bahia, especialista em Educação e em Filosofia, com mestrado em Filosofia pela Universidade Federal da Bahia. Atualmente, doutoranda do programa de Filosofia da Universidade Federal da Bahia. E-mail: lourinha.ana@hotmail.com
} 


\section{INTRODUÇÃO}

As formulações foucaultianas em torno da prática de liberdade ancoram-se em uma espécie de inquietação que nos leva a questionar de qual liberdade Foucault fala, isso no que tange pensar a liberdade como condição para o poder e vice-versa, poder esse entendido como uma prática, como ação sobre ações e não como algo que tem um locus central e que pode ser subordinado a uma categoria universal. Por isso, tomaremos como hipótese de trabalho a análise do exercício do poder caracterizado como o governo de uns pelos outros, ou seja, governo de um indivíduo sobre o outro, que implica a prática de liberdade enquanto formas de resistências e reações possíveis às formas de sujeição, de delimitação. Desse modo, buscaremos entender como o indivíduo resiste ao exercício do poder, como resiste à ação de outro que pretende determiná-lo, limitá-lo, sujeitá-lo numa relação que é ao mesmo tempo "de incitação recíproca e de luta” (FOUCAULT, 2014d, p. $134)^{2}$.

A liberdade se exercita e, por colocar-se em movimento na constituição dos indivíduos, elabora sua própria história, uma história individual criada a partir da própria experiência do sujeito. Grosso modo, tomaremos como percurso a problematização foucaultiana do exercício do poder, sob um contexto genealógico analisado a partir de 1976, tomando o poder como enfrentamento, como um modo de ação de "uns" sobre os "outros - governo de si e dos outros, ou seja, como uma ação que se exerce sobre sua própria ação, fazendo referência ao campo de condução e de governo dos outros pela verdade. É sob essa perspectiva que encontraremos nas análises de Foucault de 1978 um certo deslocamento, o qual culminará na passagem do poder ao governo ${ }^{3}$, ou seja, o filósofo francês, que no início dos anos 1970 problematiza a questão do poder no viés dos saber-poder - poder analisado como verdade e conhecimento e enquanto surgimento de saberes que possibilitam a reformulação de objetos políticos e teóricos, passa a problematizar a questão do governo, dito de outro modo, trata-se de analisar o poder na relação com as formas de governo, a qual será introduzida “incialmente, a propósito da gestão das populações e em oposição ao poder de soberania [...] o conceito de governo veio logo ocupar o centro da análise de Foucault e, definido como maneira de conduzir a conduta dos homens" (SENELLART, 2014, p. 311). Isto é, o poder passa a ser pensado "como relações entre ações livres, envolvendo ao mesmo tempo a tentativa de conduzir a ação de outrem e a resistência deste último em não se deixar ser conduzido" (CANDIOTTO, 2016, p. 32).

\footnotetext{
${ }^{2}$ FOUCAULT, M. Ditos e Escritos IX. Sujeito e o poder. 2014d, p. 118-140.

${ }^{3}$ Assim, "trata-se de se livrar, a partir dessa noção [de verdade], do tema do sabe-poder, em torno do qual tinha se organizado sua pesquisa desde o início dos anos 70. Após um primeiro deslocamento, 1978-1979, do conceito de poder para o de governo, o objetivo do curso [governo dos vivos] é 'noção de saber em direção ao problema da verdade". (SENELLART, 2014, p. 299).
} 


\section{DESENVOLVIMENTO}

\subsection{Foucault e sua genealogia do poder.}

É necessário cautela ao analisarmos as questões sobre o poder desenvolvidas por Foucault, vez que não existe uma teoria geral do poder para o filósofo francês, nem tampouco um poder que possua uma natureza, uma essência que o definiria em características universais. Foucault também não busca analisá-lo sob o viés da perspectiva econômica ou da concepção marxista. Dessa prerrogativa, nos resta dizer que é possível, para o filósofo francês, pensar o poder como uma prática social, constituída historicamente em relações de forças situadas no espaço e no tempo, tomando-o não como um poder que não se dá, nem se troca, "mas que se exerce e só existe em ato" (FOUCAULT, 2010, p. 15). Em tal caso, o poder parte de outro princípio que não a manutenção e a recondução das relações econômicas - não é uma mercadoria, mas é em si mesmo, uma relação de força. O poder aqui deve ser entendido como força que é exercida a partir de ações de "uns" sobre "outros", o que leva a outra perspectiva da análise do poder. Nessas condições, é possível apontar o poder como enfretamento, guerra continuada por outros meios - analítica do poder ${ }^{4}$.

$\mathrm{Na}$ aula de 14 de janeiro de 1976, do curso Em defesa da sociedade, Foucault (2010, p. 21) afirma que tentou apreender as regras de direito que delimitavam o poder, de um lado, e os efeitos de verdade que esse poder produz, de outro. Com efeito, seria a análise do triângulo poder, direito e verdade, ou seja, "quais são as regras de direito de que lançam mão as relações de poder para produzir discursos de verdade” (FOUCAULT, 2010, p. 22). Diante disso, é possível afirmar que em "qualquer" sociedade se formam discursos de verdade, em meio a múltiplas relações de poder, que constituem o corpo social. Dito de outro modo, "não há exercício do poder sem uma certa economia dos discursos de verdade que funcionam nesse poder, a partir e através dele", e Foucault ainda acrescenta, "somos submetidos pelo poder à produção da verdade e só podemos exercer o poder mediante produção da verdade" (FOUCAULT, 2010, p. 22).

$\mathrm{Na}$ sociedade Ocidental moderna, no entanto, essa produção da verdade se dá de modo particular, ou seja, é necessária a análise não apenas dos mecanismos da relação entre poder, direito e verdade, mas a intensidade dessa relação. Essa intensidade se apresenta na obrigação de produção da verdade pelo poder, submetendo os indivíduos a se apresentarem enquanto condenados a confessarem a verdade, dito de outro modo, uma produção de verdade a partir de um poder que questiona e não para de questionar, um poder que institucionaliza. De acordo com Foucault (2010, p. 22), isso acontece num primeiro momento, pois num segundo, ocorre a submissão à verdade, a

\footnotetext{
${ }^{4}$ Aqui ocorre uma espécie de deslocamento em relação à teoria política tradicional, que atribuía ao Estado o monopólio do poder.
}

Cadernos Cajuína, V. 6, N. 1, 2021, p. 308-325. 
verdade como norma, ou seja, um discurso verdadeiro que vai produzir efeitos de verdade. É essa a análise que o autor francês afirma tentar fazer durante seu percurso inicial.

Essa relação entre poder, direito e verdade, para um certo modo de pensar as problematizações foucaultianas aparece devido ao poder régio ${ }^{5}$ - herança da Idade Média, ou seja, desde a Idade Média, a teoria do direito tem como papel fixar a legitimidade do poder, tendo como questão central a problemática da soberania. Desse modo, relacionar o problema da teoria do direito ao problema da soberania, significa "que o discurso e a técnica do direito" tiveram como função a dissolução de um sistema de "dominação", no interior do poder, fazendo aparecer no lugar dessa dominação dois polos, a saber: direito legítimo da soberania, de um lado, e de outro, obrigação legal da obediência.

Entretanto, o filósofo francês não ancora suas análises nessas prerrogativas, visto que, o próprio Foucault (2010, p. 24) afirma tentar fazer a partir de 1971 um caminho inverso, ou seja, mostrar até onde e como o poder veicula e aplica as relações de assujeitamento, enfim, "procura discernir os procedimentos inerentes às relações entre saber e poder, num projeto" (BRANCO, 2001, p. 239) que se ampara numa concepção diferente de poder, concepção essa que deve ser recriada. Nessas condições, é feita a análise nas múltiplas sujeições que ocorrem no interior do corpo social. Desse modo, importa analisar não a posição central do soberano, ou as estratégias do soberano, mas as pequenas relações, aquelas que estão na base e que dão suporte ao soberano, a saber: os súditos e as relações recíprocas. Isso ocorre porque, segundo Foucault, são as pequenas relações que possibilitam a análise do exercício do poder.

Com efeito, podemos afirmar que Foucault busca fazer aparecer diante dessas problematizações o problema do controle e da sujeição. Diante desse problema, a pesquisa de Foucault incide nas técnicas e tecnologias do poder, ou seja, consiste em analisar como o poder domina/controla e se faz obedecer ${ }^{6}$. Para tanto, Foucault cita algumas precauções importantes para seguir com sua análise: (i) enxergar e analisar o poder lá onde ele se torna capilar, em suas bases

\footnotetext{
5 Para um certo modo de pensar a história, e também para um discurso filosófico-jurídico, uma teoria do poder não pode escapar do soberano, seja para afirmá-lo (como o discurso romano) seja para defrontá-lo (como a filosofia política moderna).

${ }^{6}$ Para analisar o pensamento é necessário entender o possível deslocamento que ocorre do eixo poder-sabersexualidade e o eixo poder-saber-subjetividade. Grosso modo, a análise que Foucault desenvolve sobre o poder desde o início de 1970 circula no âmbito da problemática verdade e poder, colocando o exercício do poder como lugar de formação do saber. No entanto, notamos nos escritos de Foucault uma passagem do poder ao governo, o qual ocorre entre os anos de 1978 e 1979, de modo que o conceito de governo ocupa um lugar central no pensamento do filosofo francês, pautado "na maneira de conduzir a conduta dos homens", deixando de lado o tema do poder-saber e colocando em pauta “o governo pela verdade". Segundo Senellart (2014, p. 316), a partir de 1980 a questão em Foucault não é mais saber como o discurso se articula à prática, "mas por que procedimento, segundo que modo, tendo em vista quais fins um sujeito se liga a uma manifestação de verdade". Foucault em 1981, com o curso Subjetividade e verdade, recentraliza suas pesquisas nas técnicas de si, técnicas essas que permitem a problematização de um sujeito "que não é permeado e informado por governamentalidades externas, mas constrói, por meio de exercícios regulares, uma relação consigo definida. O sujeito assume uma consistência ética que lhe é própria, irredutível também ao que os modernos entendem como intimidade psicológica. ” Cf. GRÒS, 2016, p. 276.
} 
regionais, ou seja, lá onde ele fornece materiais para formação das instituições e consolidação das técnicas; (ii) analisar o poder no interior das práticas reais e efetivas, ou seja, estudar o poder "do lado de sua face externa, no ponto em que ele está em relação direta e imediata com o que se pode dominar [...] seu objeto, seu alvo [...] em que ele se implanta e produz seus efeitos reais" (FOUCAULT, 2010, p. 25); (iii) consiste em não tomar o poder como uma dominação maciça e homogênea, ou seja, dominação de um indivíduo sobre outros. Segundo Foucault (2010, p. 26), o poder é circular, e ainda mais, só funciona em cadeia, “jamais ele está localizado aqui ou ali”, bem mais que isso, é necessário tomá-lo e analisá-lo como aquele que se exerce em rede. De modo geral, o poder deve ser visto como aquele que transita entre os indivíduos, que circula no meio deles, e que faz com que os indivíduos se submetam e sejam submetidos; (iv) Foucault não vê o poder como algo democrático, o qual seja distribuído de modo igual, que surja no centro e caminhe para os pontos periféricos até onde for possível, nem tampouco anárquico. De modo contrário, e como precaução ${ }^{7}$, é importante analisar o poder a partir de mecanismos infinitesimais, que "tem sua própria história, seu próprio trajeto, sua própria técnica e tática” (2010, p. 27), ou seja, tomar esses mecanismos como algo imprevisível, que não pode ser determinado e sim exercido; (v) crítica às máquinas do poder e à relação com as produções ideológicas - ideologia da educação, da democracia. Sob esse aspecto é necessário apontar que na base onde termina as redes de poder não há ideologias, o que existe são, de acordo com Foucault, instrumentos efetivos de formação e acúmulo de saber.

Por conseguinte, a questão que se colocará a partir de então, não é o que é o poder ou de onde vem, mas como se exerce, como o indivíduo nesse jogo de poder afeta o outro e é afetado, como atinge e é atingido pela ação do outo, em outras palavras, o "exercício de poder aparece como um afeto, visto que a própria força se define por seu poder de afetar outras forças e de ser afetado por outras forças" (DELEUZE, 1988, p. 79). Nesse interim, Foucault toma como ponto de partida os estudos dos corpos periféricos e múltiplos constituídos pelos efeitos de poder. Tomando o indivíduo como um dos efeitos primeiro do poder, i.e., o indivíduo é efeito do poder na mesma medida que é intermediário, "o poder transita pelo indivíduo que ele constituiu" (FOUCAULT, 2010, p. 26).

Grosso modo, as cincos precauções descritas acima nos auxiliam a se desvencilhar de uma análise e de um entendimento de um poder que reprime, que interdita, que toma como função dizer ao indivíduo “você não deve! ”. Porquanto, segundo Foucault (2010, p. 30), é necessário separar a análise do poder do modelo do Leviatã, modelo que atribui ao homem uma artificialidade,

\footnotetext{
${ }^{7}$ Isso pois, ao analisar o poder como algo democrático deixamos de lado o jogo, ou seja, o jogo agonístico, as lutas encontradas nas mais diversas relações, e passamos a determiná-lo, e isso é algo que para o filósofo francês não é possível, visto que o poder é exercido.
} 
uma autonomia produzida, que o toma como produto autônomo, fabricado em unidade iguais, os quais são vistos como cidadãos que tem como alma o soberano, enfim, poder pelo qual um homem outorga ao soberano plenos "poderes" sobre sua liberdade. Em outras palavras, não é possível ter uma análise exata da multiplicidade das relações de poder a partir do poder soberano. Nas palavras de Foucault:

\footnotetext{
Parece-me, de fato que a teoria da soberania tenta necessariamente constituir o que eu chamaria de um ciclo, o ciclo do sujeito ao sujeito, mostrar como o sujeito pode e deve se tornar sujeito, mas entendido desta vez como elemento sujeitado numa relação de poder. A soberania é a teoria que vai do sujeito para o sujeito, que estabelece a relação política do sujeito com o sujeito[...]. Em outras palavras, a teoria da soberania é o ciclo do sujeito ao sujeito, do sujeito ao poder e dos poderes, o ciclo da legitimidade e da lei (FOUCAULT, 2010, p. 37-38).
}

Com efeito, Foucault procura mostrar que a teoria da soberania toma como função modelar o sujeito, e isso, a partir de três elementos dispostos na sociedade, ou seja, o poder fundamenta o sujeito a partir do sujeito, o qual deve ser sujeito, a partir do próprio poder, e finalmente, pela legitimidade dada à lei, "sujeito, unidade do poder e lei”. Assim, o filósofo francês extrai, "histórico e empiricamente", das relações de poder, os operadores da "dominação", e parte do viés de que não é a partir da soberania ou desse ciclo do sujeito ao sujeito, que se deve analisar o poder ou as relações de poder. Em vez de "partir do sujeito", trata-se de partir das relações de poder, "da relação de dominação no que ela tem de factual, de efetivo, de ver como é essa própria relação que determina os elementos sobre os quais ela incide" (FOUCAULT, 2010, p. 38). Grosso modo, buscase substituir a análise do tripé que faz da soberania a fonte de poder e fundamentos das instituições - sujeito, unidade do poder e lei, pelo modo como os sujeitos são fabricados, passando da perspectiva da gênese da soberania para a fabricação dos sujeitos.

Assim, analisar a fabricação de sujeito, a partir de mecanismos estratégicos de poder, é analisar as relações de poder existentes "entre um homem e uma mulher", "aquele que sabe e a aquele que não sabe", "entre os pais e as crianças” (FOUCAULT, 2015a, p. 231). Essas relações são chamadas de pequenas relações de poder, relações essas que tornam possíveis a existência dos grandes poderes de Estado, pois tais poderes só funcionam com essas pequenas relações na base. É inevitável a existência dessas relações de poder na base, "pequenas relações táticas, locais e individuais" (FOUCAULT, 2015a, p. 232). Porém, estas utilizam métodos e técnicas diferentes, baseando-se em cada nível. Para esclarecer, tomemos o exemplo do pai e da criança, no qual o pai exerce seu poder através de seus próprios métodos e procedimentos para com a criança e também das crianças para com os pais, essas "relações de poder são relações de força, enfrentamentos, portanto, sempre reversíveis" (FOUCAULT, 2015a, p. 232). Segundo Branco (2001, p. 240), Foucault desenvolve uma concepção nominalista do poder na qual a ideia de posse de poder, de origem de poder são substituídas pela hipótese de que o poder está disseminado por todas as partes 
"do mundo social, numa trama complexa e heterogênea de relações de poder, na qual as resistências ao poder também tomam parte e presentificam-se".

Consequentemente, Foucault esclarece que a relações de poder abrem, a todo instante possibilidades de resistência, "de modo que é mais luta perpétua e multiforme que procuro fazer aparecer do que a dominação morna e estável de um aparelho uniformizante” (FOUCAULT, 2015a, p. 232). Essa luta está sempre acontecendo, "a revolta da criança que põe seu dedo no nariz à mesa, para aborrecer seus pais, o que é uma rebelião" (FOUCAULT, 2015a, p. 227). Segundo Machado (2017, p.18), qualquer luta é sempre resistência dentro da própria rede de poder, as quais estão sempre presente e se exercem com uma multiplicidade de relações de forças. Desse modo, as análises de Foucault sobre o poder buscam observar as infrações de poder na vida "cotidiana, nas relações entre os sexos, nas famílias, entres os doentes mentais e as pessoas sensatas, entre os doentes e os médicos, enfim, que em tudo isso, há inflação de poder” (FOUCAULT, 2015a, p. 228).

Interessa então, o caminho por onde o poder percorre, "por onde ele passa, e como isso se passa, quais são todas as relações de poder, de que modo se podem descrever algumas das principais relações de poder exercidas em nossas sociedades” FOUCAULT, 2015a, p.225). Isto posto, o poder é entendido como ações encontradas entre as pessoas, em uma família, em uma universidade, em um quartel. Diante de tais objeções, qual a relação entre a analítica do poder e a prática da liberdade?

\subsection{Relações de poder e a objetivação do sujeito}

Foucault problematiza o poder por múltiplas formas de dominação/sujeição que podem se exercer no interior do corpo social. Assim, importa analisar as pequenas relações, aquelas que estão na base e que dão suporte ao soberano. Ao analisar essas pequenas relações em suas formas múltiplas, é possível observar a questão filosófica do sujeito e produção histórica da verdade como centro: "não é, pois, o poder, mas o sujeito que constitui o tema geral de minhas pesquisas" (FOUCAULT, 2014d, p. 119). De tal modo, evidencia-se que se o sujeito está preso em relações de produção de verdade e em relações de sentido, também está preso em relações de poder. Então, faz-se necessário compreender as relações de poder para chegar ao modo como o poder toma posse do sujeito, e o leva ao assujeitamento, à submissão, ou seja, compreender “uma forma de poder que se exerce sobre a vida quotidiana imediata, que classifica os indivíduos em categorias, designaos por sua individualidade própria [...] é uma forma de poder que transforma os indivíduos em sujeitos" (FOUCAULT, 2014b, p. 123). 
Nessas condições, Candiotto (2016, p. 29) coaduna com a afirmação foucaultiana quando explica que uma das teses centrais de Foucault é a constituição do sujeito ${ }^{8}$, isso porque cada época produz os próprios objetos a partir de camadas específicas de saberes e estratégias de poder que produziram os sujeitos. Com efeito, é na relação saber e poder que podemos entender, em Foucault, a questão da constituição do sujeito como objeto com base em uma análise genealógica. De fato, a genealogia para Foucault é pensada como diagnóstico do presente, não apenas o “agora”, mas a partir do que chama de racionalidades modernas. Importante ressaltar que Foucault toma o sujeito como aquele que é livre e constituído, modelado "a cada época pelo dispositivo e pelos discursos do momento, pelas reações de sua liberdade individual e por suas eventuais 'estetizações” (VEYNE, 2014, p. 178), num processo de subjetivação.

Esses processos de subjetivação se dão na relação com a verdade e com o poder, pois a verdade tem uma relação intrínseca com o sujeito. Para tanto, encontramos, na entrevista o Sujeito e poder (1982), três métodos a partir dos quais Foucault faz seu percurso de pesquisa baseando-se na maneira como o sujeito foi objetivado pelo poder, bem como a possibilidade de criação de novos modos de subjetivação. Trata-se da problematização do sujeito objetivado, ou seja, "a produção de uma história dos diferentes modos de subjetivação do ser humano" (FOUCAULT, 2014b, p. 118), a saber: (i) modo de investigação (estatuto da ciência), que está pautado na objetivação do sujeito que produz, que trabalha; (ii) a objetivação das práticas divisoras, que se constitui pela divisão do sujeito em seu interior e em relação aos outros, isto é, a divisão do homem em louco e são, bandido e "homem de bem", rapaz e marginal etc; e, (iii) a constituição do sujeito, ou seja, como o ser humano torna-se sujeito. Grosso modo, trata-se de uma ontologia de nós mesmos em relação à verdade, que nos constitui como sujeitos de saber; uma ontologia de nós mesmo num campo do poder, que nos constitui como sujeitos de ação; e uma ontologia da relação ética, que nos constitui enquanto agentes morais.

De acordo com Foucault (2015, p. 224), há efeitos de verdade que a sociedade produz a cada instante, e esses efeitos não podem ser dissociados dos mecanismos de poder, uma vez que esses mecanismos de poder tornam possíveis essas produções de verdades, produções essas que a partir dos efeitos do poder unem e atam os indivíduos. Nas palavras de Foucault:

As relações de poder suscitam necessariamente [...], abrem a possibilidade a uma resistência, e é porque há possibilidade de resistência e resistência real que o poder daquele que domina tenta se manter com tanto mais força, tanto mais astúcia, quanto maior for a resistência [...]. Em toda parte, se está em luta [...] e, a cada instante se vai da rebelião à dominação, da dominação à rebelião. (FOUCAULT, 2015, p. 227).

\footnotetext{
${ }^{8}$ Candiotto (2016, p. 30) explica que sujeito em Foucault é uma espécie de atribuição, uma linguagem, "uma objetivação vinculada à cientificidade de um saber nascido de práticas concretas".
} 
Nesse interim, o filósofo francês mostra a necessidade de analisar a economia das relações de poder através dos "antagonismos das estratégias", pois as relações de poder "são relações de força, de enfrentamento [...] sempre reversíveis" (FOUCAULT, 2015, p.227), que buscam colocar em xeque as formas de resistências contra as diferentes formas de poder. Nas palavras do autor, "para compreender o que são as relações de poder, talvez devêssemos investigar as formas de resistência e as tentativas de dissociar estas relações" (FOUCAULT, 2014c, p. 121). Diante disso, a resistência emerge nos interstícios do poder, por meio de um deslocamento em relação às diversas formas existentes de sujeição.

Grosso modo, é crucial analisar duas perspectivas do pensamento do filósofo francês para se chegar ao jogo agonístico poder-liberdade, a saber: em primeiro lugar, a questão do poder e sua importância na sociedade, numa relação direta com a produção das várias formas de resistências. Trata-se do que Foucault chama de analítica do poder, ou seja, pensar o poder não apenas como manutenção e recondução das relações econômicas, i.e., para entender os procedimentos do poder é necessário liberar-nos do privilégio teórico da lei e da soberania, "é necessário construir uma analítica do poder que não tome mais o direito como modelo e código" (FOUCAULT, 2014c, p. 99). Desse modo, é necessário uma análise iniciada pela base, que tome como "modelo" as relações de poder, as quais estão em todos os lugares: “o homem contra a mulher, entre aquele que sabe e aquele que não sabe, na família [...] na sociedade, há milhares e milhares de relações de poder [...] relações de força e enfrentamentos, microlutas" (FOUCAULT, 2014c, p. 226). Trata-se, de modo geral, de saber, nesses mecanismos de poder, "por onde passa, como se passa, entre quem e quem... segundo quais procedimentos e com quais efeitos" (FOUCAULT, 1978, p. 3-4).

Em segundo lugar, fazer uma análise da relação entre poder e verdade, pois os efeitos de verdade que a sociedade produz a cada instante não pode ser dissociado dos mecanismos de poder, pois são esses "mecanismos de poder [que] tornam possíveis essas produções de verdades, as quais tem elas próprias efeitos de poder que nos une” (FOUCAULT, 2015, p. 224).

\subsection{Contraconduta como prática de resistência aos modos de sujeição}

Diante do deslocamento ocorrido no pensamento de Foucault, o qual sai da análise podersaber para a análise poder-governo, problematizaremos que às formas de governo se apresentam como modos e técnicas pautadas no jogo poder e liberdade. Para tanto, nos embasaremos em Candiotto quando esclarece a possibilidade de notar um deslocamento no pensamento de Foucault no que diz respeito à analítica do poder, posto que até 1976 a questão central em Foucault consiste em analisar a constituição de um sujeito sujeitado, ou seja, o indivíduo é controlado pela norma e 
regulado pelo biopoder. Porém, a partir de 1978, percebemos no pensamento de Foucault uma mudança de perspectiva, sendo possível identificar uma constituição agonística do sujeito, sublinhando a perspectiva da liberdade como potência. Assim, Foucault se vê frente a uma problemática diferente dá até então analisada, tomando como ponto central as possibilidades de transformação do mundo por intermédio de práticas contestadoras?:

[Foucault] passa a estudar o papel das resistências, em todas as suas dimensões, na trama complexa das relações de poder na atualidade, seus antecedentes históricos e suas perspectivas de êxito. Seu interesse passa a ser os combates e as lutas inerentes às relações de poder, e não a descrição das grandes articulações institucionais e políticas que formam as grandes estruturas de poder e que persistem num largo espaço de tempo (BRANCO, 2001, p. 242).

Trata-se da análise das relações de poder no âmbito das diversas formas de lutas, de combate, de resistências, as quais se fazem presentes num jogo agonístico ${ }^{10}$ entre o poder e liberdade. Em outras palavras, é nesse jogo agonístico que o indivíduo, na sua prática de liberdade, i.e., fazendo uso de estratégias de confronto para inversão das relações de poder e suas regras de produção de verdade, se efetiva e resiste ao exercício de poder, nessa conjuntura, é possível entender o processo de resistir e efetivação como uma atitude crítica.

Grosso modo, para que seja possível fazer a análise histórica da atitude crítica, iniciada especificamente entre os séculos XV- XVI, a qual o indivíduo faz parte de um jogo entre liberdade e poder, é necessário investigar a questão crítica. Desse modo, a crítica, na conjuntura do poder e de sua contestação, pode ser entendida como virtude, que se desenvolve e desemboca num emaranhado de caminhos. Assim, explica Foucault que sua problematização consiste tenta fazer esse modo de análise a partir da pastoral cristã - segundo o qual todo indivíduo deve ser governado e se deixar governar, i.e., "deixar-se dirigir para a sua salvação, por alguém a quem o ligue a uma relação global e ao mesmo tempo meticulosa, detalhada obediente” (FOUCAULT, 2015, p. 33).

A partir das análises feita no curso Segurança, Território e população, Foucault, passa a analisar as formas de governo como jogos estratégicos, jogos nos quais um tentará determinar a conduta do outro, e, por conseguinte, o outro, que em alguma medida foi conduzido, tentará não se deixar determinar, e vice-versa. Entendemos como jogo estratégico às formas de resistências/contracondutas, ou seja, o enfrentamento estratégico a ser exercido pelo indivíduo diante da tentativa de normalização disciplinar e da regulamentação do biopoder instaurados na sociedade moderna, ou seja, luta contra os procedimentos postos em prática para conduzir os

\footnotetext{
${ }^{9}$ Essas práticas são observadas por Foucault a partir de suas análises sobre organização política do Irã e os modos de insurreições lá desenvolvidos. Cf. AFARY; ANDERSON, Foucault e a revolução iraniana: relações de gênero e as soluções do Islamismo.

${ }^{10} \mathrm{O}$ conceito de agonismo sugere, em Foucault, um combate permanente entre indivíduos e grupos onde existe a constante possibilidade de liberdade de ação e a pré-condição da emergência das relações de poder.
} 
outros. É nessa perspectiva que Branco dirá que o poder, para o Foucault "tardio", se volta para a contribuição criativa das lutas de resistências. Afirma Branco:

Em sua última fase, quer mostrar o quanto está interessado em contribuir para o processo criativo das lutas de resistência, que constituem uma nova economia das relações de poder, pois 'tudo isto está diretamente ligado a uma prática e a estratégias que são, por sua vez, móveis e se transformam'. A criatividade das estratégias e das lutas, portanto, decorrem das artimanhas da liberdade. Sua investigação, a partir desse contexto, 'consiste em tomar as formas de resistência aos diferentes tipos de poder como ponto de partida' (BRANCO, 2001, p. 243).

Com efeito, é a partir desses jogos estratégicos que as práticas de resistências são possíveis enquanto práticas de liberdade. Grosso modo, é no poder pastorado ${ }^{11}$, por exemplo, e em suas instituições que se desenvolvem algumas práticas de resistências analisadas por Foucault, práticas essas que tem como função transformar os procedimentos de individualização que se caracterizam pela sujeição e pela subjetivação. A esses procedimentos, Foucault chama de história da sujeição. Desse modo, podemos dizer que a história do sujeito ocidental moderno se faz presente, de um modo novo, a partir do pastorado cristão ${ }^{12}$. Diante disso, o filósofo francês aponta já na análise do pastorado o que posteriormente chamará de governamentalidade ${ }^{13}$, afirmando que esse pastorado preludia a governamentalidade de duas maneiras, as quais se desenvolveram a partir do século XVI, a saber: pelos procedimentos específicos do pastorado ${ }^{14}$ e pela constituição de um sujeito ${ }^{15}$ "cujos os méritos são identificados de maneira analítica, de um sujeito que é sujeitado em redes contínuas de obediência, de um sujeito que é subjetivado pela extração da verdade que lhe é imposta" (FOUCAULT, 2008, p. 243). A constituição do sujeito se deu a partir do desenvolvimento de um movimento que leva ao que Foucault chama de arte de governar - arte pedagógica, política e das instituições de governo.

Consoante Foucault (2008, p. 254), o pastorado se apresenta como um conjunto de técnicas e procedimentos, e diante disso, podemos salientar que algumas dessas técnicas já existiam, e que foram assimiladas e reinventadas pela espiritualidade cristã para servir a fins absolutamente

\footnotetext{
${ }^{11}$ Não estamos aqui a afirmar que Foucault toma como formas de resistências apenas as práticas desenvolvidas no pastorado cristão, mas optamos por analisar, a partir de suas problematizações, como, nesse período, foram desenvolvidas essas práticas e como, se possível, elas estão relacionadas ao que, mais tarde, vem a ser a atitude crítica. ${ }^{12}$ De modo geral, Foucault analisa o poder pastorado e suas especificidades por duas razões: de um lado, como o próprio filósofo afirma "não existe moral judaico-cristã", e de outro, porque não há nas sociedades ocidentais modernas uma relação entre política e religião que esteja ligada diretamente à Igreja e ao Estado, o que há é uma relação entre pastorado e governo. Assim, é a relação entre pastorado e governo que vai justificar o estudo feito pelo filósofo francês.

13 "O processo ou antes, o resultado do processo pelo qual o Estado de Justiça da Idade Média, que nos séculos XV e XVI se tornou o Estado administrativo, viu-se pouco a pouco 'governamentalizado"' (FOUCAUTL, 2008, p. 144145), ou seja, processos, reflexões, táticas que permitiam exercer a forma do poder, especificamente sobre a população. ${ }^{14}$ Deslocação em relação ao seu núcleo religioso, laicização, bem como expansão na sociedade civil da arte de governar os homens e dos métodos para tal. CF. Foucault, 2015, p. 33.

${ }^{15}$ Por exemplo, governo das crianças, governos dos pobres e dos mendigos, enfim, os diferentes grupos, cidades e Estados.
} 
desinteressantes aos gregos. Por exemplo, nos gregos a economia era vista como um procedimento totalmente familiar, já no cristianismo vai “incidir sobre a comunidade de todos os cristãos e sobre a vida de cada um em particular [...] vai se tratar não apenas da propriedade e da riqueza da família ou da casa, mas da salvação das almas" (FOUCAULT, 2008, p. 254). Foucault explica que a palavra economia pode ser traduzida pelos latinos por regime - regime das almas, no entanto quando traduzida para o francês tem um sentido ambíguo. Por isso, o filósofo francês toma de empréstimo, a partir de textos de Montaigne a palavra "conduta ${ }^{16 "}$, referindo-se a duas coisas: a questão do conduzir; e a questão de como uma pessoa se conduz e se deixa conduzir.

O pastorado cristão, a partir do século XVI, passa por uma "espécie de crise”, a qual, de certo modo, abre espaço para o surgimento de questões que estão na dimensão da governamentalidade, questões essas diretamente ligadas aos pontos "limitadores" de resistências ${ }^{17}$ de ataque e contra-ataque que surgem no meio do pastorado. O que leva o pastorado a sofrer essa crise? O que Foucault pretende ao analisar essa crise? Foucault esclarece, que não tenta fazer uma história do pastorado e de seus limitadores externos, e sim tentar pesquisar alguns pontos de resistências, de contra-ataques que puderam se produzir no próprio campo do pastorado. Desse modo, problematizar o surgimento do governo é possível, segundo Foucault, quando se pressupõe que o pastorado seja um tipo de poder específico que se dá por objeto da conduta dos homens, e que possibilita o aparecimento de movimentos contrários a esse poder, a saber: movimentos específicos de resistências, de insubmissões, de revoltas:

São movimentos que têm como objetivo outra conduta, isto é: querer ser conduzido de outro modo, por outros condutores e por outros pastores, para outros objetivos e para outras formas de salvação, por meio de outros procedimentos e de outros métodos [...] que procuram em todo caso, escapar da conduta dos outros, que procuram definir para cada um a maneira de se conduzir. (FOUCAULT, 2008, p. 257).

As revoltas de conduta têm sua especificidade, pois, de acordo com Foucault (2008, p. 258), elas se distinguem dos modos de revoltas contra o poder, na medida em que exerce uma espécie de soberania. "São distintas em sua forma, são distintas em seu objetivo". Por isso que a maior revolta de conduta de que se tem notícia, conhecida pelo ocidente cristão, é a de Lutero, que de início não era nem econômica e nem política. No entanto, essa distinção não as separa, ou desloca, pelo contrário, afirma Foucault (2008, p. 259), elas estão sempre ligadas a outros conflitos ou a

\footnotetext{
${ }^{16}$ Segundo Foucault (2008, p. 255), essa noção de condução abarca um dos elementos fundamentais introduzidos pelos pastorado cristão no mundo ocidental.

17 "Resistencia, por exemplo, secular à prática, à obrigação da confissão imposta pelo concílio de Latrão em 1215. Resistências ativas também, com que o pastorado se chocou frontalmente, sejam elas práticas que podemos chamar de extracristãs - até que ponto elas o eram é outra questão, como, digamos, a bruxaria, ou ainda choques frontais com as grandes heresias" (FOUCAULT, 2008, p. 256).
} 
outros problemas ${ }^{18}$. Todas essas revoltas de conduta citadas por Foucault, que datam do início do cristianismo até o final do século XVII, têm suas especificidades, porém "nunca são autônomas".

De tal modo, quando Foucault aborda as relações de poder, estar por tomar os indivíduos como produtores que estão em uma situação estratégica, a qual abrirá uma possibilidade para transformação das coisas. De tal modo, afirma Foucault:

Porque nós somos homossexuais, por exemplo, estamos em luta contra o governo, e o
governo está em luta contra nós. Quando tratamos com o governo, a luta, é claro, não é
simétrica, a situação do poder não é a mesma, mas nós participamos juntos dessa luta.
Um de nós leva vantagem sobre o outro, e o prolongamento dessa situação pode
determinar a conduta a seguir, influenciar a conduta, ou a não conduta, do outro. Não
somos, então, presos como em uma armadilha. Ora, estamos sempre nesse gênero de
situação. O que quer dizer que temos sempre a possibilidade de mudar a situação, que
essa possibilidade existe sempre. Não podemos sempre transformar a situação. Eu não
quis, então, dizer que estamos sempre presos como em uma armadilha, mas, ao contrário,
que estamos sempre livres. Enfim, em resumo, que há sempre a possibilidade de
transformar as coisas (FOUCAULT, 2014d, p. 256).

Por conseguinte, é no interior dessa dinâmica, dessa situação estratégica que encontramos a resistência, pois a resistência só ocorre, e só é possível quando os indivíduos envolvidos estão em condição de liberdade. Nesse interim, a relação entre liberdade e poder é circular, e é circular porque existe a possibilidade de resistência, ou seja, o indivíduo pode tanto ser o comandante da situação quanto o comandado, dependendo apenas do modo como eles utilizam a resistência. "Do instante em que o indivíduo está em situação de não fazer o que ele quer, ele deve utilizar relações de poder. A resistência vem, então, em primeiro lugar, e ela fica superior a todas as forças de processos" (FOUCAULT, 2014d, p. 257), obrigando a relações de poder a mudarem. De acordo com Branco (2008, p. 206), toda experiência, "seja de exercício de liberdade, seja de dominação nas relações de poder, ocorre tão somente em ato". Em outras palavras, o poder e a resistência ao poder são faces da mesma moeda, nessa relação, no entanto, pode ocorrer equilíbrio, mas nunca uma paz, pois o exercício de liberdade e as relações de poder estão em um constante jogo agonístico. Nesse viés, os dois polos geram contextos éticos e políticos sempre provisórios, uma vez que é um jogo passível de transformação:

É até mesmo possível que certas relações de dominação possam perdurar — séculos ou milênios, em certas partes do planeta: todavia, isto não quer dizer que suas relações de poder não tenham passado por transformações inevitáveis, resultado dos constantes enfrentamentos, das resistências ao poder, nem quer dizer que estruturas de poder aparentemente inabaláveis um dia caiam por terra. É incontestável: não há, não houve, nem haverá Estado, relações de poder, Impérios que durem eternamente (BRANCO, 2008, p. 206-207).

\footnotetext{
${ }^{18}$ É possível encontrar resistências de conduta, por exemplo, em toda a Idade Média - a burguesia e o feudalismo, bem como, ligada ao deslocamento que se produziu no século XII - economia urbana e rural. Encontraremos também nos conventos femininos, em meio ao estatuto das mulheres. Também na direção de consciência do século XVII. Cf. FOUCAULT, 2008, p. 259.
} 
Grosso modo, o enfrentamento agonístico, segundo Branco (2008, p. 207), pressupõe campos de lutas sempre abertos que funcionam no jogo entre as estratégias de poder e a prática de liberdade, visto que não há uma relação imutável/cristalizada, que permaneça eternamente sem ser transformada. Nessas condições, politicamente, o elemento mais importante das relações de poder é a resistência, não a resistência que simplesmente diz não, pois o dizer "não" consiste em uma forma mínima de resistência, e o processo de resistência vai além, pois transforma a situação, cria e recria. De acordo com Foucault (2017, p. 341-342), é preciso analisar o conjunto das resistências em termos estratégicos e de tática, "vendo que cada ofensiva serve de ponto de apoio a uma contraofensiva". De modo, que a análise dos mecanismos de poder não tende a mostrar um poder, ao mesmo tempo, anônimo e sempre vencedor, é antes demarcar as posições e os modos de ação de cada um, bem como as possibilidades de resistências e de contra-ataque de uns e de outros, por exemplo: as lutas individualizantes contra as tecnologias do poder desenvolvidas nas sociedades atuais e que tem como principal representante o Estado. Esclarece Branco:

Para Foucault, essas são lutas de resistência contra o gigantesco aparato, técnicas e
procedimentos desenvolvidos para conhecer, dirigir e controlar as vidas das pessoas, seus
estilos de existência, suas maneiras de sentir, avaliar, pensar. Essas técnicas e saberes,
dentro do projeto de otimização do poder, têm o objetivo explícito de conhecer e
controlar a vida subjetiva de cada um dos membros submetidos aos seus campos de ação,
de maneira que Foucault alerta que a técnica característica do poder moderno é dispor,
simultaneamente, de técnicas totalizantes e procedimentos que visam ao "governo por
individuação". O governo por individuação ou normalização, dizendo de outra maneira
na terminologia de Foucault, é o substituto contemporâneo do poder pastoral
desenvolvido no passado pela Igreja (BRANCO, 2001, p. 245).

Diante disso, as práticas de resistências possibilitam ao indivíduo a recusa ${ }^{19}$ desses procedimentos e técnicas impostas pelo outro, desse governo pela individualização, ou seja, permite ao indivíduo resistir aos modelos e práticas limitadoras e normalizadoras, e com isso praticar a liberdade. Visto que para Foucault a questão central que devemos ter em mente não é descobrir quem somos, e sim recusar quem somos, a partir da produção, invenção e criação de novos modos de subjetivação, novos estilos de vidas, novos modos de resistências, para além das formas implantadas pelas técnicas modernas. Nessas condições, o indivíduo passa, a partir das estratégias de resistência, a praticar essa recusa do que é, pois ele se vê inserido em um ambiente de individualização que precisa ser combatido. Desse modo, as relações de poder são modos de ação que não agem diretamente e nem imediatamente sobre os outros, mas sobre suas próprias ações: "Uma ação sobre ação, sobre ações eventuais[...] que se abra, diante de relação de poder, todo um campo de respostas, reações, efeitos, invenções possíveis” (FOUCAULT, 2014d, p. 133).

\footnotetext{
${ }^{19}$ Não uma grande recusa, mas modos de resistências no plural, pois são possíveis, improváveis, violentas, necessários, solitárias.
} 
Ao fazer a análise dentro das relações de poder, numa perspectiva da ação sobre ação do indivíduo, no deparamos no pensamento de Foucault com o termo "conduta", pois, é o que permite com mais êxito compreender o que há de específico nas relações de poder. Visto que a conduta é, "ao mesmo tempo, o ato de conduzir os outros e a maneira de se comportar em um campo mais ou menos aberto de possibilidades" (FOUCAULT, 2014d, p. 133), ou seja, de possibilidades de resistir. Desse modo, o exercício do poder dentro das relações de poder se faz na ordem do enfretamento entre dois indivíduos ou entre grupos de indivíduos. Consoante Foucault (2014a, p. 134), ao definirmos o exercício do poder como um campo de ações sobre ações dos outros, estamos abrindo para um elemento importante, que é a liberdade:

\begin{abstract}
O poder só se exerce sobre "sujeitos livres", e enquanto são "livres" - entendamos por isso sujeitos individuais ou coletivos que têm diante de si um campo de possibilidades em que várias condutas, várias reações e diversos modos de comportamento podem apresentar-se. Aí onde as determinações são saturadas não há relação de poder: a escravidão não é uma relação de poder quando o homem está acorrentado (trata-se, então, de relação física de obrigação), mas justamente quando ele pode deslocar-se e, no limite, escapar. Não há uma face a face do poder e da liberdade, com uma relação de exclusão entre eles (por toda a parte onde o poder se exerce, a liberdade desaparece); mas um jogo muito mais complexo: nesse jogo, a liberdade vai aparecer como condição de existência do poder" (FOUCAULT, 2014d, p. 134).
\end{abstract}

Com efeito, como apontamos acima, Foucault coloca a liberdade como condição de existência para o poder, porquanto os dois fazem parte de uma relação circular, desse modo não podemos pensar o poder anulando a liberdade, isto pois, a prática de liberdade é pensada paralela a resistência, sendo uma condição para à prática da outra, visto que "para resistir, é preciso que a resistência seja como o poder. Tão inventiva, tão móvel, tão produtiva quanto ele" (FOUCAULT, 2017, p. 360). Desse modo, não podemos pensar a substituição da liberdade pelo poder, dado que “compreender o exercício do poder como prática de governo, como controle das condutas em um campo de possibilidades, pressupõe que os sujeitos implicados nas relações de poder sejam livres" (GALLO, 2013, p. 358). Acontece que não há a separação entre a relação de poder e insubmissão da liberdade. O que há é a luta, um jogo "agonístico", ou seja, uma luta que é ao mesmo tempo de incitação recíproca e combate. Trata-se de uma luta que só é possível quando os "sujeitos" são livres, os quais se veem em uma situação aberta a reação, a resistência, e resistência forte às técnicas de poder que são hegemônicas.

\title{
3.Considerações finais
}

A partir das análises acimas, entendemos que quando o indivíduo resiste a certos efeitos do poder, a certos modos de dominação e resiste de modo crítico e reflexivo, num espaço aberto pelas relações de poder, ele estará a praticar a liberdade, a qual consiste em última instância, no enfrentamento de si mesmo, na criação de formas outras de si, formas outras de não ser mais o 
mesmo, de "não querer ser governado de tal modo" e mudando a si muda-se a realidade, enfrentando a sujeição, o assujeitamento, constituindo-se como indivíduo autônomo, aberto a constituição de formas outras de subjetividades.

Assim, enquanto efetivação da prática de liberdade, a crítica se mostra como recusa do que somos no momento presente, como recusa de modos de enunciação que delimitam a forma como o indivíduo deve conduzir sua vida - seja individual, seja coletivo. Recusa a partir de um corpo que responderá a cada uma das imposições do poder por meio da fala, da expressão excessiva ou não, do modo como se veste, como caminha, como usa seus adereços, usa seu cabelo, enfim o modo como se conduz. Desvelando, assim, as práticas discursivas e não discursivas que caracterizam o mundo moderno. Com efeito, a consciência do corpo não poder ser apenas adquirida pelo efeito e "investimento do corpo pelo poder (...). Mas, a partir do momento em que o poder produziu esse efeito, na própria linha de suas conquistas, emerge inevitavelmente a reivindicação de seu corpo contra o poder, a saúde contra a economia, o prazer contra as normas morais da sexualidade...” (FOUCAULT, 2014d, p. 259).

Grosso modo, o objetivo dessa recusa é a necessidade de resistir às formas de poder que totalizam a população, que transformam o indivíduo em sujeitos, que o subjugam e submetem, visto que a ontologia de nós mesmos é a própria atitude crítica, e quando o indivíduo desenvolve essa atitude, desenvolve também um modo de ser, um êthos, uma autonomia que tende a recusar os tipos de limitações impostas pelo outro.

Portanto, ao propor o diagnóstico do presente como tarefa de sua filosofia, Foucault pensou a possibilidade de práticas de liberdade, ou seja, de uma relação refletida de resistência aos campos de saber e de poder que formam nossa atualidade, isto é, "uma ontologia de nós mesmos". A qual consiste na saída de si mesmo, na tentativa de torna-se outro que aquilo que se é, enquanto desdobramento da liberdade. Trata-se pensar a liberdade como uma prática possível no interior dos sistemas de verdade formados por campos de saber e poder, uma prática pautada no enfrentamento de nós mesmos. Nessas condições, o indivíduo sempre estará diante de relações de poder, quando exerce o poder ou quando é atravessado por ele, às vezes em condições de sujeito, e às vezes de sujeito hegemônico, mas nunca de modo definitivo, pois sempre existe a possibilidade de resistência, de mudança. Desse modo, tomamos os escritos de Foucault como ferramenta para pensar a atualidade, visto que a tarefa de seus livros é "servir a usos não definidos por aquele que os escreveu. Quanto mais houver usos novos, possíveis, imprevistos" (FOUCAULT, 2012, p. 36), melhor será. Desse modo, analisar, refletir e problematizar sobre os modos de controle e regulamentação existentes na sociedade é papel do indivíduo e, bem mais, do "intelectual”, do 
pesquisador que busca viver uma ontologia crítica do presente, mediante o recomeço e o repensar dos modelos sociais pré-constituídos, criando práticas possíveis de resistências.

\section{REFERÊNCIAS}

AFARY, Janet; ANDERSON, Kevin. Foucault e a revolução iraniana. São Paulo: realizações editoras, 2011.

BRANCO, Guilherme Castelo. As resistências ao poder em Michel Foucault. Transformação, São Paulo, 24: 237-248, 2001.

BRANCO, Guilherme Castelo. Atitude-limite e relações de poder: uma interpretação sobre o estatuto da liberdade em Michel Foucault. Verve, São Paulo, 13: 202-216, 2008.

BRANCO, Guilherme Castelo. Governamentalidade, política, resistência ao poder. Política: pensamento e ação. 1. ed. Belo Horizonte: Autêntica editora, 2016.

CANDIOTTO, Cesar. A genealogia da ética de Michel Foucault. Educação e Filosofia, Uberlândia, v. 27, n. 53, p. 217-234, jan./jun. 2013.

CANDIOTTO, Cesar. Ética e política em Michel Foucault. Transformação, Marília, v. 33, n. 2, p. 157-176, 2010.

CANDIOTTO, Cesar. Foucault e a crítica do sujeito e da história. Revista Aulas, Dossiê Foucault, n. 3. 2007.

CANDIOTTOO, Cesar. Sujeito, agonística e seus desdobramentos políticos no pensamento de Michel Foucault. Desdobramentos, 1 ed. Belo Horizonte: Autêntica editora, 2016.

EDGARDO, Castro. Vocabulário de Foucault: um percurso pelos seus temas, conceitos e autores. Tradução: Ingrid Müller Xavier. 2. Ed. Belo Horizonte: Autêntica, 2016.

FOUCAULT, Michel. O cuidado de si como prática da liberdade. Ditos e escritos: Ética, sexualidade, política. Organização de textos Manoel Barros da Motta. Trad. Elisa Monteiro, Inês Autran Dourado Barbosa. 3. Ed. Rio de Janeiro: Forense Universitária, 2014b. V. 5.

FOUCAUlT, Michel. A cultura de si. Trad. Pedro Elói Duarte. São Paulo: Ed. Textos \& grafia, 2015c.

FOUCAULT, Michel. A hermenêutica do sujeito: Curso do Collège de France. Edição: Frédéric Gros. Trad. Marcio Alves Fonseca, Salma Tannus Muchail 3. Ed. São Paulo: Editora Martins Fontes, 2014a.

FOUCAULT, Michel. Em defesa da sociedade: curso no Collège de France. Trad. Maria Ermantina Galvão. $2^{\mathrm{a}}$ ed. São Paulo: editora Martins Fontes, 2010.

FOUCAULT, Michel. Estratégia, poder-saber: organização de textos e seleção Manoel Barros Motta. Trad. Vera Lucia Avellar Ribeiro. 2. Ed. Rio de Janeiro: Forense Universitária, 2015a. V. 4. 
FOUCAULT, Michel. História da sexualidade I: A vontade de saber. Trad. Maria Thereza Albuquerque e J. A. Albuquerque. 1. Ed. Rio de Janeiro: Paz e Terra, 2014c.

FOUCAULT, Michel. História da Sexualidade II: O uso dos prazeres. Trad. De Maria Thereza da Costa Albuquerque. Rio de Janeiro: editora Graal, 1984. V. 2.

FOUCAULT, Michel. Michel Foucault, o Ilegalismo e a Arte de Punir. Ditos e escritos: Segurança, penalidade e prisão. Organização Manoel Motta. Trad. Vera Lucia Ribeiro. - Rio de Janeiro: Forense, 2012. V.8.

FOUCAULT, Michel. Microfísica do poder. Organização Roberto Machado, 5 ed. Rio de Janeiro: Paz e Terra, 2017.

FOUCAULT, Michel. O que é a crítica? Trad. Pedro Elói Duarte. São Paulo: Ed. Textos \& grafia, 2015.

FOUCAULT, Michel. O sujeito e Poder. Ditos e escritos IX: Genealogia da ética, subjetividade e sexualidade. Organização de textos e seleção Manoel Barros da Motta. Trad. Abner Chiquieri. Rio de Janeiro: Forense Universitária, 2014d. V. 9.

FOUCAULT, Michel. Segurança, território, população: Curso no Collège de France. Trad. Eduardo Brandão. São Paulo: Martins Fontes, 2008.

FOUCAULT, Michel. Sobre a genealogia da Ética: uma visão do trabalho em andamento. Dossiê: últimas entrevistas. Dreyfus e Rabinow. São Paulo: Editora Taurus, 1983.

FOUCAULT, Michel. Vigiar e punir: o nascimento da prisão. Trad. Raquel Ramalhete. 42 eds. Petrópolis, Rio de Janeiro: Vozes, 2014.

GUT'TING, Gary. Foucault. Tradução: André Oídes. São Paulo: Ideias \& Letras, 2016.

MACHADO, Roberto. Por uma genealogia do poder. In: Microfísica do poder. Organização Roberto Machado, 5. ed. Rio de Janeiro: Paz e Terra, 2017.

RABINOW, Paul; DREYFUS, Hubert. Michel Foucault Uma trajetória Filosófica: Para além do estruturalismo e da hermenêutica. Trad. Sob a direção de Vera Porto Carrero. Forense Universitária.

REVEL, Judith. Foucault Conceitos Essenciais. Trad. Sob a direção de Carlos Piovezani Filho e Nilton Milanez. São Carlos: Editora Claraluz, 2005. 96p.

SENELLART, Michel. Situação do curso: Governo dos vivos. Tradução Eduardo Brandão. São Paulo: Editora Martins Fontes, 2014.

SENELLART, Michel. Situação do curso: In:Segurança, território e população. Tradução Eduardo Brandão. São Paulo: Editora Martins Fontes, 2008.

VEYNE, Paul. Foucault: seu pensamento, sua pessoa. Tradução de Marcelo Jacques de Moraes. 2. Ed. Rio de Janeiro: Civilização brasileira, 2014. 